\title{
Compound 8i
}

Qualitative Analysis Report

\section{Data Filename \\ Sample Type}

Instrument Name

Acq Method

IRM Calibration Status
F8-150.d

Sample

Instrument 1

ESI+20-100\%_12min.m

Not Applicable
Sample Name

Position

User Name

Acquired Time 4/28/2017 4:03:42 PM

DA Method ChromPeakSurvey-Default.m

Comment

User Chromatograms

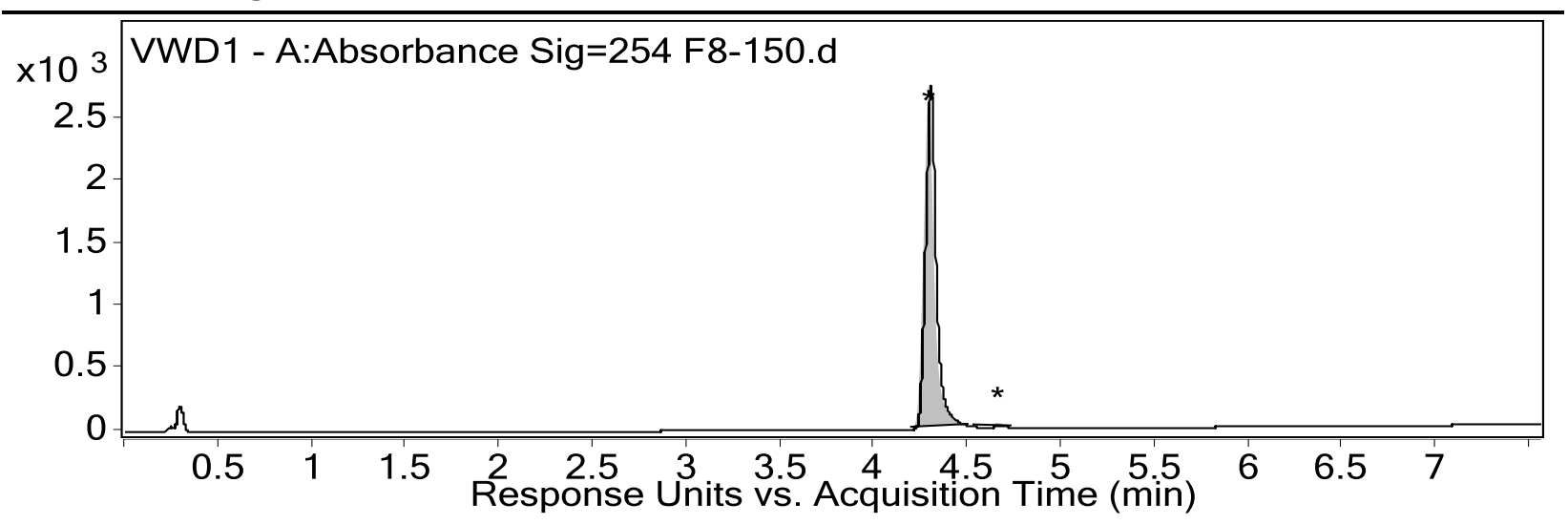

Integration Peak List

\begin{tabular}{|r|r|r|r|r|r|r|}
\hline Peak & \multicolumn{1}{l|}{ Start } & RT & \multicolumn{1}{l|}{ End } & \multicolumn{1}{l|}{ Height } & \multicolumn{1}{l|}{ Area } & \multicolumn{1}{|l|}{ Area \% } \\
\hline 1 & 4.2 & 4.3 & 4.51 & 2731.45 & 10790.87 & 100 \\
\hline 2 & 4.53 & 4.66 & 4.74 & 17.57 & 40.2 & 0.37 \\
\hline
\end{tabular}

Fragmentor Voltage

165

Collision Energy

0 Ionization Mode ESI

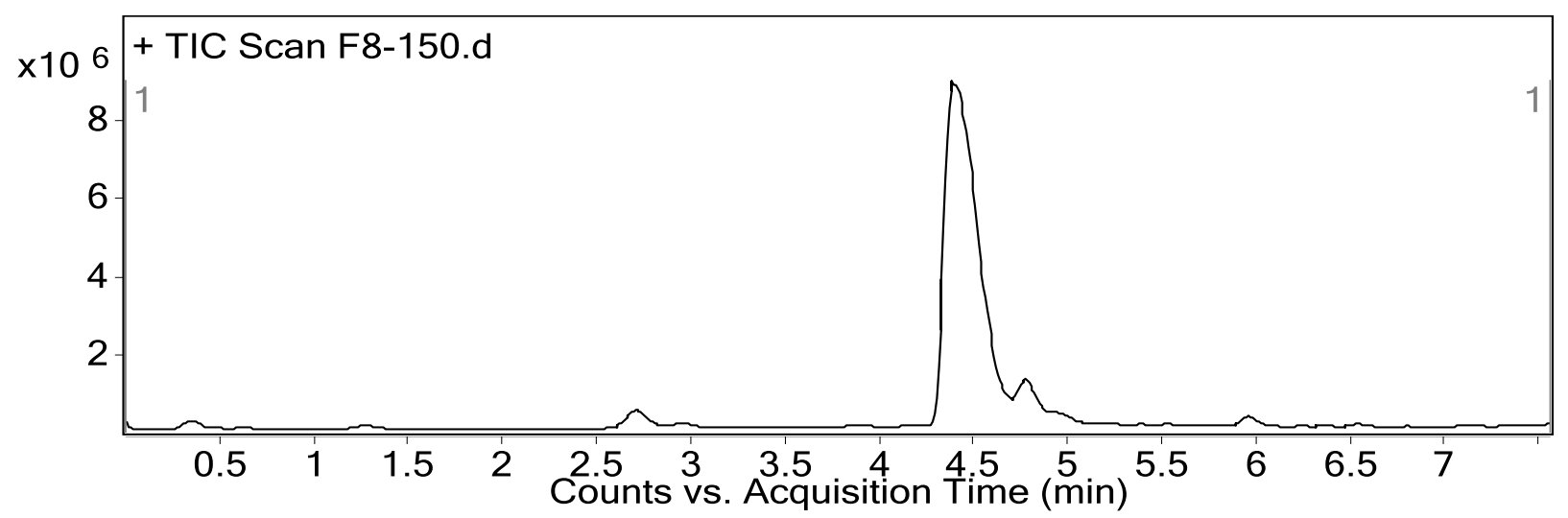

User Spectra

Fragmentor Voltage

Collision Energy

Ionization Mode

165

0

Esi 


\section{Qualitative Analysis Report}

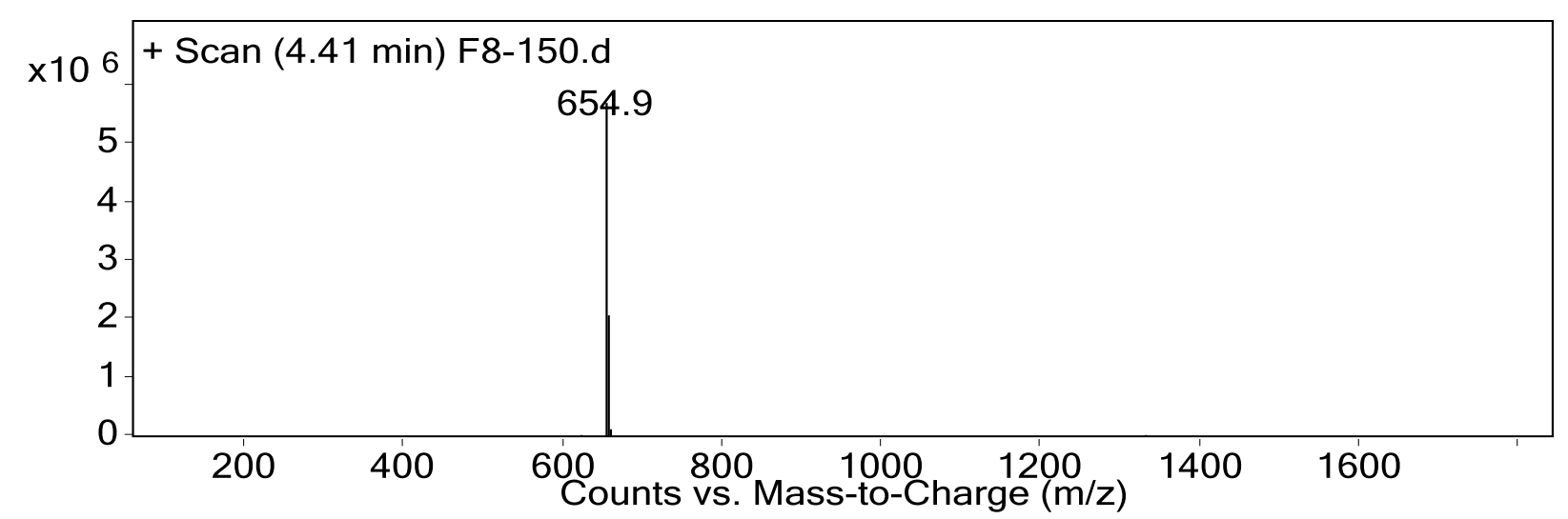

Peak List
\begin{tabular}{|l|l|l|}
\hline $\boldsymbol{m} / \boldsymbol{z}$ & z & Abund \\
\hline 654.9 & 1 & 5718987 \\
\hline 655.9 & 1 & 2063765 \\
\hline 656.9 & 1 & 644758 \\
\hline
\end{tabular}

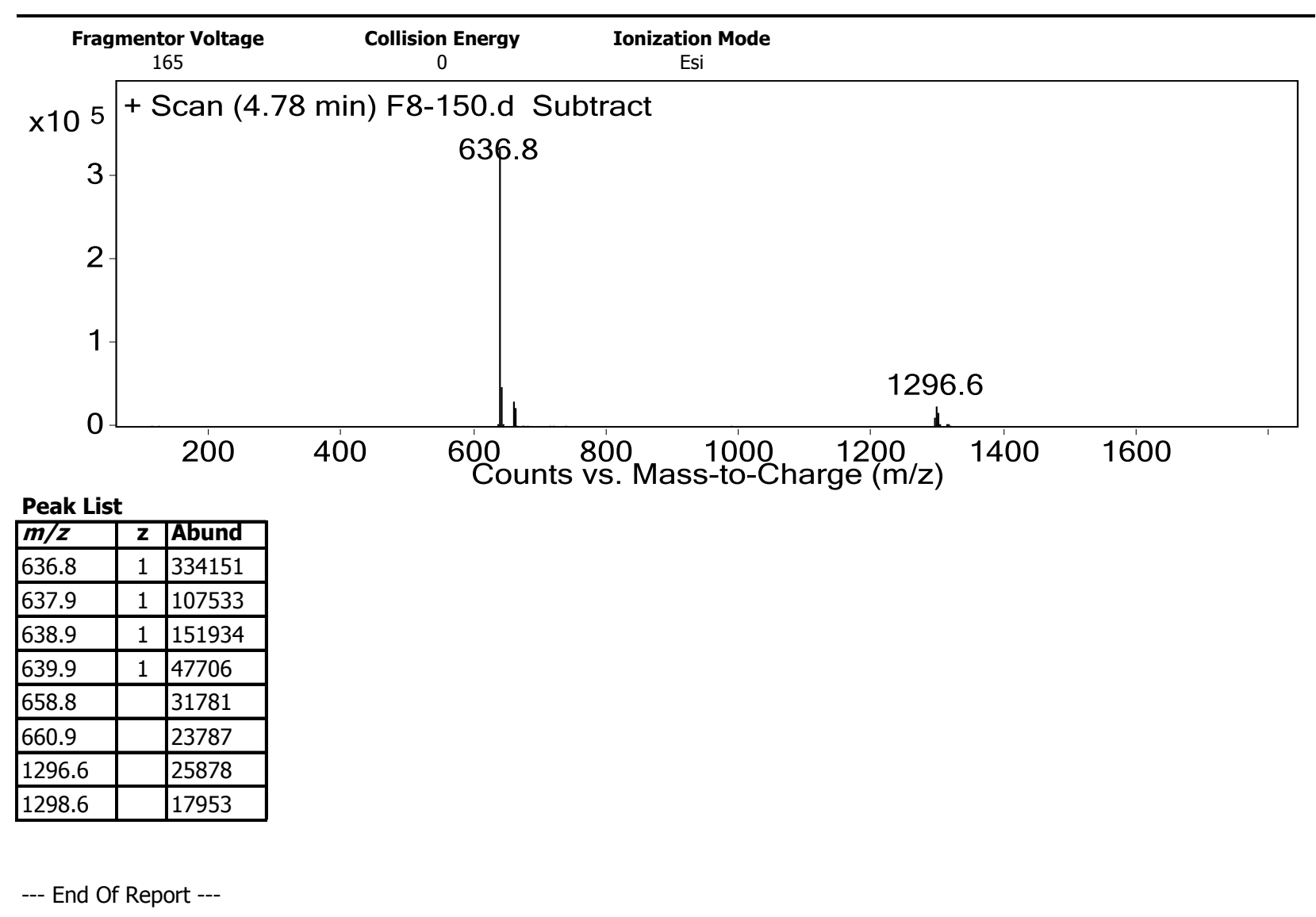

